\title{
Implementasi Metode Inferensi Fuzzy Tsukamoto Untuk Memprediksi Curah Hujan Dasarian Di Sumenep
}

\author{
Isnaini Muhandhis ${ }^{1}$, Alven S. Ritonga ${ }^{2}$ dan M. Harist Murdani ${ }^{3}$ \\ 1,2,3 Prodi Teknik Informatika, Universitas Wijaya Saputra, Surabaya, Indonesia \\ email: ${ }^{1}$ isnainimuhandhis@uwp.ac.id
}

\begin{abstract}
Abstrak
Peramalan curah hujan diperlukan untuk membantu memprediksi awal musim karena anomali cuaca yang sering terjadi saat ini. Pada penelitian ini kami melakukan peramalan curah hujan dasarian di Sumenep menggunakan metode inferensi fuzzy Tsukamoto. Hasil peramalan curah hujan dengan metode inferensi fuzzy Tsukamoto memiliki akurasi yang baik dengan nilai MAPE 10,64\%. Peramalan dengan fuzzy Tsukamoto dapat memprediksi awal musim kemarau yaitu pada Dasarian 3 bulan April tahun 2020. Adapun prediksi awal musim hujan adalah Dasarian 2 di bulan November 2020.
\end{abstract}

Kata Kunci: sistem penunjang keputusan; sistem informasi; ramalan cuaca.

\section{Abstract}

Rainfall forecasting is needed to help predict the beginning of the season because of the weather anomalies that often occur at this time. In this research, we forecast the basic rainfall in Sumenep Regency using the Tsukamoto fuzzy inference method. The results of rainfall forecasting using the Tsukamoto fuzzy inference method have good accuracy with a MAPE value of $10.64 \%$. Forecasting with fuzzy Tsukamoto can predict the start of the dry season, namely on Dasarian 3 in April 2020. The prediction of the start of the rainy season is Dasarian 2 in November 2020.

Keywords: decision support system; information system; weather forecasting. 


\section{PENDAHULUAN}

Pemanasan global menyebabkan suhu permukaan bumi naik dan mempengaruhi iklim dan cuaca. Saat ini, sering terjadi anomali cuaca sehingga datangnya musim sulit diprediksi (Arnel \& Reynard, 1996). Oleh karena itu, peramalan curah hujan diperlukan untuk membantu memprediksi datangnya musim hujan dan musim kemarau. Dengan mengetahui datangnya musim hujan dan musim kemarau maka para stakeholder yang terkait dapat memanfaatkan informasi tersebut untuk mengambil tindakan. Misalnya, petani dapat mengatur waktu tanamnya sehingga terhindar dari kegagalan panen. Wisatawan dapat mengetahui waktu yang tepat untuk berlibur dan banyak manfaat lainnya.

Pada penelitian ini, kami melakukan peramalan curah hujan menggunakan metode inferensi fuzzy Tsukamoto. Ada banyak metode yang digunakan untuk prediksi curah hujan seperti (Desmonda et al., 2018), (Hasan et al., 2018) dan (Harmoko et al., 2015). FIS Tsukamoto juga sering digunakan untuk peramalan cuaca dengan berbagai macam variabel input (Wahyuni et al., 2016). Fuzzy Tsukamoto telah banyak digunakan untuk memprediksi data pada (Mazenda et al, 2014) dan (Ferdiansyah \& Hidayat, 2018). Pada penelitian ini kami menggunakan empat variabel masukan yang terdiri dari data curah hujan periode yang sama pada empat tahun sebelumnya. Peramalan serupa pernah dilakukan oleh (Wahyuni et al., 2016) dan memiliki akurasi yang cukup baik.

Selain metode inferensi Tsukamoto, ada banyak metode lain untuk melakukan peramalan curah hujan seperti (Muhandhis et al., 2020) dan (Muhandhis et al., 2020). Pada penelitian ini peneliti membandingkan hasil peramalan antara ketiga metode tersebut untuk mengetahui metode yang terbaik. Hasil peramalan ini diharapkan dapat memberikan informasi penunjang pada stakeholder terkait peramalan musim, dan memberikan pengetahuan tentang metode peramalan yang terbaik.

\section{METODE PENELITIAN \\ Pengumpulan Data}

Data curah hujan dasarian Stasiun Klimatologi Kalianget didapatkan dari situs resmi Badan Meteorologi, Klimatologi dan Geofisika (BMKG). Data curah hujan periode tahun 2016-2019 digunakan sebagai data histori untuk membuat aturan fuzzy, sedangkan data tahun 2020 digunakan sebagai acuan data peramalan hujan dasarian.

\section{Metode inferensi fuzzy Tsukamoto}

Pada metode Tsukamoto merepresentasikan setiap aturan dengan bentuk IF-THEN yang monoton. Hasil dari perhitungan $\alpha$-predikat setiap aturan diubah menjadi nilai tegas (crisp). Hasil akhirnya diperoleh dengan menggunakan rata-rata terbobot (Maryaningsih et al., 2013).

Langkah penyelesaian dengan fuzzy Tsukamoto (Ferdiansyah \& Hidayat, 2018):

1. Fuzzifikasi

Fuzzifikasi mengubah masukan sistem yang memiliki nilai crisp menjadi satu set nilai samar (fuzzy) kemudian menentukan nilai derajat keanggotaan dalam setiap himpunan fuzzy.

2. Pembentukan Rules IF-Then

Proses untuk membentuk Rule yang akan digunakan dalam bentuk IF -THEN yang tersimpan dalam basis keanggotaan fuzzy.

3. Mesin Inferensi

Keluaran fuzzy didapatkan dari perubahan nilai masukan fuzzy dengan cara fuzzifikasi setiap aturan IF-THEN yang telah ditentukan di awal. Tsukamoto menggunakan fungsi implikasi MIN untuk mendapatkan nilai $\alpha$-predikat setiap aturan. Kemudian, setiap nilai $\alpha$-predikat digunakan untuk menghitung nilai $\mathrm{Z}$ atau keluaran dari tiap-tiap aturan.

4. Defuzzifikasi

Tahap akhir adalah proses defuzzifikasi yang mengubah hasil keluaran fuzzy yang diperoleh dari mesin inferensi menjadi nilai tegas atau crisp. Hasil akhir diperoleh dengan 
menggunakan persamaan rata-rata pembobotan penjumlahan nilai $\mathrm{Z}$ dengan jumlah $\alpha$-predikat dari keseluruhan Rules.

\section{Perhitungan akurasi peramalan}

Metode peramalan bertujuan untuk menghasilkan ramalan optimum yang tidak memiliki tingkat kesalahan besar. Metode yang digunakan untuk mengukur tingkat akurasi pada penelitian ini adalah MAPE (Mean Absolute Percentage Error) yang ada pada persamaan 1.

$$
\text { Mape }=\frac{100 \%}{n} \sum_{t=1}^{n} \mid \frac{X_{t}-\dot{X}_{t}}{X_{t}}
$$

dengan $X_{t}$ adalah data aktual pada waktu t dan $\dot{X}_{t}$ adalah data hasil peramalan pada waktu t. Kriteria keakuratan MAPE yaitu jika $<10 \%$ maka ketepatan peramalan sangat baik, jika nilai MAPE antara $10 \%$ - 20\% ketepatan peramalan baik, sedangkan nilai 20\% - 50\% ketepatan peramalan cukup, dan jika nilai MAPE > 50\% maka ketepatan peramalan tidak akurat.

\section{HASIL DAN PEMBAHASAN}

\section{Pendefinisian Masalah}

Pada penelitian ini, peramalan curah hujan dilakukan berdasarkan data histori curah hujan periode yang sama dengan data empat tahun sebelumnya sebagai variabel masukan. Data diambil dari Dasarian 1 Januari 2016 sampai Dasarian 3 Desember 2019. Keempat variabel tersebut disimbolkan dengan Z t$1, \mathrm{Z} \mathrm{t}-2, \mathrm{Z} \mathrm{t}-3$ dan $\mathrm{Z} \mathrm{t}-4$. Adapun $\mathrm{Z} \mathrm{t}$ adalah simbol data curah hujan yang akan diramalkan. Sebelum memulai perhitungan dengan logika fuzzy, data curah hujan perlu diamati dulu untuk mengetahui jangkauan data curah hujan di tiap periode, seperti terlihat pada Tabel 1.

Tabel 1. Jangkauan data curah hujan

\begin{tabular}{ccc}
\hline No & Variabel & Jangkauan \\
\hline 1 & Z t-1 & $0-287$ \\
2 & Z t-2 & $0-183$ \\
3 & Z t-3 & $0-184$ \\
4 & Z t-4 & $0-236$ \\
5 & Z t & $0-208$ \\
\hline
\end{tabular}

Tabel 2 merupakan sampel variabel masukan yang digunakan untuk meramal data curah hujan pada tahun 2020 sebanyak 36 data.

Tabel 2. Sampel data input

\begin{tabular}{ccc}
\hline Jumlah Data & Variabel Masukan & Data \\
\hline 1 & $\mathrm{Z} \mathrm{t}-1$ & 13,8 \\
& $\mathrm{Z} \mathrm{t}-2$ & 163 \\
& $\mathrm{Z} \mathrm{t}-3$ & 114,7 \\
& $\mathrm{Z} \mathrm{t}-4$ & 43,4 \\
\hline 2 & $\mathrm{Z} \mathrm{t}-1$ & 37 \\
& $\mathrm{Z} \mathrm{t}-2$ & 110 \\
& $\mathrm{Z} \mathrm{t}-3$ & 106,6 \\
& $\mathrm{Z} \mathrm{t}-4$ & 114,7 \\
$\vdots$ & $\vdots$ & $\vdots$ \\
\hline 36 & $\mathrm{Z} \mathrm{t}-1$ & 101,4 \\
& $\mathrm{Z} \mathrm{t}-2$ & 65,7 \\
& $\mathrm{Z} \mathrm{t}-3$ & 182,5 \\
& $\mathrm{Z} \mathrm{t}-4$ & 108,3 \\
\hline
\end{tabular}




\section{Fuzzifikasi}

Himpunan fuzzy merupakan komponen yang mewakili kondisi tertentu dari variabel fuzzy (Mazenda et al, 2014). Dalam penelitian ini, penggunaan himpunan fuzzy memiliki tiga nilai linguistik yaitu rendah, sedang dan tinggi. Pembentukan nilai linguistik himpunan fuzzy disesuaikan dengan data curah hujan yang ada.

Terdapat lima variabel fuzzy yang akan dimodelkan. Variabel pertama adalah data tahun 2019 (Zt1), data tahun 2018 (Zt-2), data tahun 2017 (Zt-3), data tahun $2016(\mathrm{Zt}-4)$ dan data peramalan tahun 2020 (Zt). Setiap variabel memiliki 3 nilai linguistik yaitu rendah (r), sedang (s) dan tinggi (t).

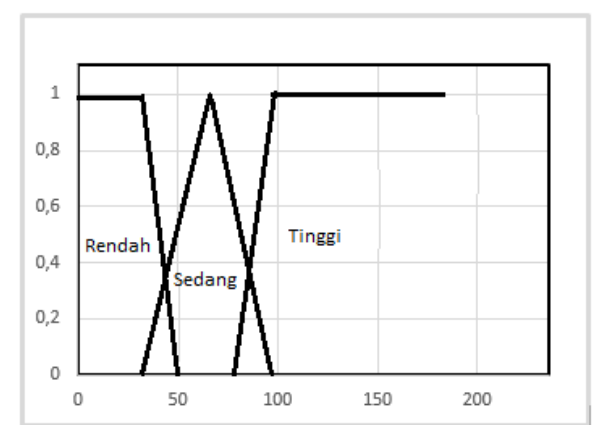

Gambar 1. Fungsi keanggotaan himpunan fuzzy untuk semua variabel masukan

Fungsi keanggotaan himpunan fuzzy untuk semua variabel input (Zt-1, Zt-2, Zt-3 dan Zt-4) adalah sama seperti pada Gambar 1.

Derajat keanggotaan nilai rendah:

$$
\mu Z t(1-4)[r]=\left\{\begin{array}{c}
1 ; x<30 \\
\frac{50-x}{50-30} ; 30 \leq x \leq 50 \\
0 ; x>50
\end{array}\right.
$$

Derajat keanggotaan nilai sedang:

$$
\mu Z t(1-4)[s]=\left\{\begin{array}{c}
0 ; x<30 \\
\frac{x-30}{65-30} ; 30<x \leq 65 \\
\frac{.00-x}{100-65} ; 65<x \leq 100 \\
0 ; x>100
\end{array}\right.
$$

Derajat keanggotaan nilai tinggi:

$$
\mu Z t(1-4)[t]=\left\{\begin{array}{c}
0 ; x<80 \\
\frac{x-80}{100-80} ; 80<x \leq 100 \\
1 ; x \geq 100
\end{array}\right.
$$

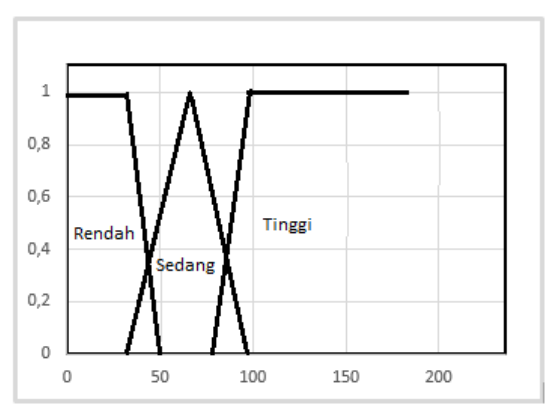

Gambar 2. Fungsi keanggotaan himpunan fuzzy untuk Zt 
Derajat keanggotaan nilai rendah:

$\mu Z t[r]=\left\{\begin{array}{c}1 ; x<30 \\ \frac{50-x}{50-30} ; 30 \leq x \leq 50 \\ 0 ; x>50\end{array}\right.$

Derajat keanggotaan nilai sedang:

$$
\mu Z t[s]=\left\{\begin{array}{c}
0 ; x<30 \\
\frac{x-30}{65-30} ; 30<x \leq 65 \\
\frac{100-x}{100-65} ; 65<x \leq 100 \\
0 ; x>100
\end{array}\right.
$$

Derajat keanggotaan nilai tinggi:

$$
\mu Z t[t]=\left\{\begin{array}{c}
0 ; x<80 \\
\frac{x-80}{100-80} ; 80<x \leq 100 \\
1 ; x \geq 100
\end{array}\right.
$$

\section{Metode Inferensi Fuzzy Tsukamoto}

Tahap pertama menjalankan inferensi Fuzzy Tsukamoto adalah membentuk aturan "IF-THEN" kemudian menghitung derajat keanggotaan setiap variabel linguistik pada data. Setelah mengetahui nilai derajat keanggotaan, maka kita dapat menghitung nilai $\alpha$-predikat. Kemudian menghitung keseluruhan nilai $\alpha$-predikat dikali nilai $\mathrm{Z}$ tiap rule. Penelitian ini menggunakan 20 aturan fuzzy yang tertulis pada Tabel 3. Tabel 4 adalah contoh perhitungan derajat keanggotaan setiap variabel linguistik dari $\alpha$-predikat aturan 1 sampai 20. Fuzzy Tsukamoto menggunakan fungsi implikasi MIN, sehingga setiap nilai variabel dicari nilai minimal di tiap rule.

Tabel 3. Aturan Fuzzy

\begin{tabular}{cccccc}
\hline No & Z t-1 & $\mathbf{Z ~ t}-\mathbf{2}$ & $\mathbf{Z ~ t}-\mathbf{3}$ & $\mathbf{Z}$ t-4 & Keputusan \\
\hline 1 & $\mathrm{R}$ & $\mathrm{R}$ & $\mathrm{R}$ & $\mathrm{R}$ & Rendah \\
2 & $\mathrm{R}$ & $\mathrm{R}$ & $\mathrm{R}$ & $\mathrm{S}$ & Rendah \\
3 & $\mathrm{R}$ & $\mathrm{R}$ & $\mathrm{R}$ & $\mathrm{T}$ & Rendah \\
4 & $\mathrm{R}$ & $\mathrm{R}$ & $\mathrm{S}$ & $\mathrm{S}$ & Rendah \\
5 & $\mathrm{R}$ & $\mathrm{R}$ & $\mathrm{T}$ & $\mathrm{R}$ & Sedang \\
6 & $\mathrm{R}$ & $\mathrm{R}$ & $\mathrm{T}$ & $\mathrm{S}$ & Rendah \\
7 & $\mathrm{R}$ & $\mathrm{S}$ & $\mathrm{S}$ & $\mathrm{R}$ & Sedang \\
8 & $\mathrm{R}$ & $\mathrm{S}$ & $\mathrm{S}$ & $\mathrm{S}$ & Sedang \\
9 & $\mathrm{R}$ & $\mathrm{S}$ & $\mathrm{T}$ & $\mathrm{R}$ & Sedang \\
10 & $\mathrm{R}$ & $\mathrm{T}$ & $\mathrm{T}$ & $\mathrm{S}$ & Sedang \\
11 & $\mathrm{~S}$ & $\mathrm{~S}$ & $\mathrm{~S}$ & $\mathrm{~S}$ & Sedang \\
12 & $\mathrm{~S}$ & $\mathrm{~S}$ & $\mathrm{~S}$ & $\mathrm{R}$ & Sedang \\
13 & $\mathrm{~S}$ & $\mathrm{~S}$ & $\mathrm{R}$ & $\mathrm{S}$ & Sedang \\
14 & $\mathrm{~S}$ & $\mathrm{R}$ & $\mathrm{S}$ & $\mathrm{T}$ & Sedang \\
15 & $\mathrm{~S}$ & $\mathrm{~T}$ & $\mathrm{~S}$ & $\mathrm{~S}$ & Sedang \\
16 & $\mathrm{~S}$ & $\mathrm{~T}$ & $\mathrm{~T}$ & $\mathrm{R}$ & Sedang \\
17 & $\mathrm{~T}$ & $\mathrm{~S}$ & $\mathrm{~S}$ & $\mathrm{~S}$ & Sedang \\
18 & $\mathrm{~T}$ & $\mathrm{~T}$ & $\mathrm{~T}$ & $\mathrm{~S}$ & Tinggi \\
19 & $\mathrm{~T}$ & $\mathrm{~T}$ & $\mathrm{~S}$ & $\mathrm{~T}$ & Tinggi \\
20 & $\mathrm{~T}$ & $\mathrm{~T}$ & $\mathrm{~T}$ & $\mathrm{~T}$ & Tinggi \\
\hline
\end{tabular}


Keterangan:

$\mathrm{R}=$ rendah

$\mathrm{S}=$ sedang

$\mathrm{T}=$ Tinggi

\section{Defuzzifikasi}

Defuzzikasi mengubah nilai yang dihasilkan mesin inferensi menjadi nilai tegas dengan persamaan 2 .

$$
Z=\frac{\sum(\alpha-\text { predicate } i * Z i)}{\sum \alpha-\text { predicate } i}
$$

Keterangan:

$\mathrm{Z}=$ hasil defuzifikasi rata-rata terbobot

$\alpha$-predicate $=$ nilai minimum derajat keanggotaan

$\mathrm{Zi}=$ nilai crisp yang didapat dari hasil inferensi

$\mathrm{i}=$ jumlah aturan fuzzy

\section{Perhitungan akurasi peramalan}

Hasil perbandingan peramalan ke-36 data curah hujan dasarian pada tahun 2020 dengan data asli dan hasil perhitungan akurasi dengan MAPE dapat dilihat pada Tabel 5.Akurasi peramalan dihitung dari D1 bulan Januari hingga D3 bulan Oktober. Adapun D1 bulan Nopember sampai D3 bulan Desember adalah nilai prediksi dari fuzzy Tsukamoto. Nilai perhitungan akurasi peramalan dengan MAPE sebesar $10,64 \%$ yang artinya peramalan memiliki akurasi yang baik.

Tabel 4. Perhitungan inferensi fuzzy Tsukamoto

\begin{tabular}{cccccc}
\hline No & $\mathbf{Z ~ t - 1}$ & $\mathbf{Z}$ t-2 & $\mathbf{Z}$ t-3 & $\mathbf{Z ~ t - 4}$ & $\boldsymbol{\alpha}$-pred $* \mathbf{Z}$ \\
\hline 1 & 0,33 & 0 & 0 & 1 & 0 \\
2 & 0,33 & 0 & 0 & 0 & 0 \\
3 & 0,33 & 0 & 0 & 0 & 0 \\
4 & 0,33 & 0 & 0 & 0 & 0 \\
5 & 0,33 & 0 & 1 & 1 & 0 \\
6 & 0,33 & 0 & 1 & 0 & 0 \\
7 & 0,33 & 0 & 0 & 1 & 0 \\
8 & 0,33 & 0 & 0 & 0 & 0 \\
9 & 0,33 & 0 & 1 & 1 & 0 \\
10 & 0,33 & 0 & 1 & 0 & 0 \\
11 & 0,38 & 0 & 0 & 0 & 0 \\
12 & 0,38 & 0 & 0 & 1 & 0 \\
13 & 0,38 & 0 & 0 & 0 & 0 \\
14 & 0,38 & 0 & 0 & 0 & 0 \\
15 & 0,38 & 1 & 0 & 0 & 0 \\
16 & 0,38 & 1 & 1 & 1 & 33,15 \\
17 & 0 & 0 & 0 & 0 & 0 \\
18 & 0 & 1 & 1 & 0 & 0 \\
19 & 0 & 1 & 0 & 0 & 0 \\
20 & 0 & 1 & 1 & 0 & 0 \\
\hline \multicolumn{5}{c}{$\sum \alpha$-predikat * Z } & 33,15 \\
\hline
\end{tabular}


Proses defuzifikasi untuk data pada tabel 4 adalah:

$$
Z=\frac{33,15}{0,38}=86,6
$$

Berdasarkan BMKG, musim kemarau ditandai dengan curah hujan dasarian kurang dari $50 \mathrm{~mm}$ 3 kali berturut-turut (Giarno et al., 2012). Jika kita lihat pada Tabel 5, maka musim kemarau pada data asli dimulai pada D3 bulan April. Waktu yang sama juga ditunjukkan pada data peramalan, yang artinya metode peramalan dapat menunjukkan waktu awal musim kemarau dengan akurat.

Perlu dicatat bahwa musim kemarau sangat jarang terjadi sebelum bulan April bedasarkan data curah hujan di stasiun klimatologi Kalianget dalam 20 tahun terakhir.

Tabel 5. Perbandingan hasil peramalan dan data curah hujan

\begin{tabular}{|c|c|c|c|c|}
\hline Waktu & Data & $\begin{array}{c}\text { Peramalan } \\
\text { Fuzzy }\end{array}$ & $\left(\mathbf{Y}_{\mathbf{t}}-\mathbf{Y}_{\mathbf{p}}\right) / \mathbf{Y}_{\mathbf{t}}$ & MAPE \\
\hline D1Jan & 191 & 86,6 & 0,55 & 10,64 \\
\hline D2Jan & 24,6 & 84 & 2,45 & \\
\hline D3Jan & 106 & 100 & 0,05 & \\
\hline D1Feb & 148 & 84,5 & 0,43 & \\
\hline $\mathrm{D} 2 \mathrm{Feb}$ & 208 & 74,9 & 0,64 & \\
\hline D3Feb & 72,8 & 84 & 0,15 & \\
\hline D1Mar & 133 & 82,7 & 0,38 & \\
\hline D2Mar & 38,8 & 89 & 1,29 & \\
\hline D3Mar & 29 & 41 & 0,42 & \\
\hline D1Apr & 46 & 58,9 & 0,27 & \\
\hline D2Apr & 129 & 93,7 & 0,27 & \\
\hline D3Apr & 26 & 46,7 & 0,77 & \\
\hline D1Mei & 16 & 37,5 & 1,31 & \\
\hline D2Mei & 43 & 30 & 0,31 & \\
\hline D3Mei & 68,8 & 42,7 & 0,38 & \\
\hline D1Jun & 10,1 & 30 & 1,97 & \\
\hline D2Jun & 2,7 & 39 & 13,4 & \\
\hline D3Jun & 0 & 39,7 & 39,7 & \\
\hline D1Jul & 43 & 41,2 & 0,04 & \\
\hline D2Jul & 1,5 & 31 & 19,6 & \\
\hline D3Jul & 0 & 30,8 & 30,8 & \\
\hline D1Agt & 0 & 30 & 30 & \\
\hline D2Agt & 10 & 30 & 1,9 & \\
\hline D3Agt & 0 & 30 & 30 & \\
\hline D1Sep & 0 & 30 & 30 & \\
\hline D2Sep & 0 & 30 & 30 & \\
\hline D3Sep & 0 & 30 & 30 & \\
\hline D1Okt & 0 & 33,6 & 33,6 & \\
\hline D2Okt & 43,4 & 42,3 & 0,025 & \\
\hline D3Okt & 1,7 & 32,9 & 18,3 & \\
\hline D1Nop & - & 35,8 & - & \\
\hline D2Nop & - & 65 & - & \\
\hline D3Nop & - & 87,8 & - & \\
\hline D1Des & - & 77,7 & - & \\
\hline D2Des & - & 34,2 & - & \\
\hline D3Des & - & 99,6 & - & \\
\hline
\end{tabular}


Oleh karena itu, terjadinya curah hujan dasarian kurang dari $50 \mathrm{~mm} 3$ kali berturut-turut sebelum April dapat diabaikan. Berdasarkan hasil peramalan maka musim hujan di Sumenep akan dimulai pada D2 bulan Nopember 2020. Graf perbandingan hasil peramalan dan data curah hujan dapat dilihat pada Gambar 3.

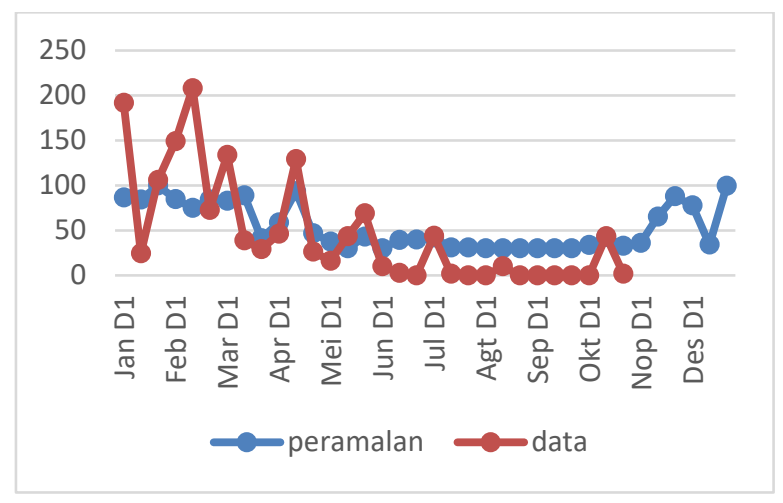

Gambar 3. Graf perbandingan data dan peramalan curah hujan

Kami telah melakukan perhitungan dengan beberapa metode fuzzy lainnya pada data curah hujan yang sama yang dapat dilihat perbandingannya pada Tabel 6 .

Tabel 6. Perbandingan akurasi peramalan

\begin{tabular}{cccc}
\hline No & Metode & MAPE & Referensi \\
\hline 1 & FIS Tsukamoto & $10,64 \%$ & - \\
2 & FTS Cheng & $5,6 \%$ & (Muhandhis et al., 2020) \\
3 & FTS Markov-Chain & $6,46 \%$ & (Muhandhis et al., 2020) \\
\hline
\end{tabular}

\section{KESIMPULAN}

Peramalan curah hujan dengan metode inferensi fuzzy Tsukamoto memiliki akurasi yang baik dengan nilai MAPE 10,64\%. Adapun perbandingan dengan metode fuzzy lain yang sebelumnya kami gunakan, metode terbaik dengan nilai MAPE paling kecil yaitu 5,6\% adalah metode Fuzzy Time Series Cheng. Hasil peramalan terbaik kedua adalah metode Average Based Fuzzy Time Series Markov-Chain. Pembentukan jangkauan nilai linguistik pada himpunan fuzzy sangat berpengaruh terhadap hasil akhir peramalan.

Peramalan dengan Fuzzy Inference System Tsukamoto dapat memprediksi awal musim kemarau dengan tepat di tahun 2020. Adapun prediksi awal musim hujan adalah Dasarian 2 di bulan November 2020 .

\section{DAFTAR PUSTAKA}

Arnell, N and Reynard, N., (1996). The effects of climate change due to global warming on river flows in Great Britain, J. Hydrol., vol. 183, no. 3-4, pp. 397-424.

Desmonda, D., Tursina, T., and Irwansyah, M. A., (2018). Prediksi Besaran Curah Hujan Menggunakan Metode Fuzzy Time Series. JUSTIN J. Sist. Dan Teknol. Inf., vol. 6, no. 4, pp. 145-149.

Ferdiansyah, Y. and Hidayat, N. (2018). Implementasi Metode Fuzzy-Tsukamoto Untuk Diagnosis Penyakit Pada Kelamin Laki Laki. J Pengemb Teknol Inf Dan Ilmu Komput E-ISSN, vol. 2548, p. $964 \mathrm{X}$. 
Giarno, G., Dupe, Z. L., and Mustofa, M. A. (2012). Kajian Awal Musim Hujan dan Awal Musim Kemarau di Indonesia. J. Meteorol. Dan Geofis., vol. 13, no. 1.

Harmoko, I. W., Nazori, A., and others. (2012). Prototipe model prediksi peluang kejadian hujan menggunakan metode fuzzy logic tipe mamdani dan sugeno. J. TICom, vol. 1, no. 1, p. 94049.

Hasan, N., Nath, N. C., and Rasel, R. I. (2015). A support vector regression model for forecasting rainfall. 2nd International Conference on Electrical Information and Communication Technologies (EICT), pp. 554-559.

Maryaningsih, M., Siswanto, S., and Mesterjon, M. (2013). Metode Logika Fuzzy Tsukamoto Dalam Sistem Pengambilan Keputusan Penerimaan Beasiswa. Media Infotama, vol. 9, no. 1, p. 150752.

Mazenda, G., Soebroto, A. A., and Dewi, C. (2014). Implementasi Fuzzy Inference System (FIS) metode Tsukamoto pada sistem pendukung keputusan penentuan kualitas air sungai. J. Environ. Eng. Sustain. Technol., vol. 1, no. 2, pp. 92-103.

Muhandhis, I., Ritonga, A. S., and Murdani, M. H. (2020). PERAMALAN CURAH HUJAN MENGGUNAKAN METODE AVERAGE-BASED FUZZY TIME SERIES MARKOV CHAIN. Pros. SNasPPM, vol. 5, no. 1, pp. 118-122.

Muhandhis, I., Susanto, H., and Asfari, U. (2020). Paper title: Determining Salt Production Season Based on Rainfall Forecasting Using Weighted Fuzzy Time Series. J. Appl. Comput. Sci. Math., vol. 14 , no. 30, pp. 23-27.

Wahyuni, I., Mahmudy, W. F., and Iriany, A. (2016). Rainfall prediction in Tengger region Indonesia using Tsukamoto fuzzy inference system. 1st International Conference on Information Technology, Information Systems and Electrical Engineering (ICITISEE), pp. 130-135. 
